\section{Gaia metaphor unfalsifiable}

SIR-Jim Lovelock's nice-guy image may not last if he persists in responding to his critics by impugning their motives. Biologists, he says, "seem to see Gaia as another threat to the sanctity of their creature, neo-darwinism". Reductionists, he says, are engaged in a "dogmatic crusade". Lovelock apparently even sees fit to accuse me of a witch hunt: "like some figure of the Inquisition, he publicly burned several imaginary Gaias, and his pyrotechnic demolition of the strong Gaia stole the show. But when the sparks faded, the real system Gaia was still there hidden only by the smoke" .

Lovelock neglects to note that my criticism is available in the literature ${ }^{2}$. Others may judge for themselves whether the Gaias I address, drawn verbatim from Lovelock's publications between 1974 and 1988, are "imaginary" or not.

Now, has the "real system Gaia" (Lovelock's most recent Gaia, also called "geophysiology") gone up in flames? Lovelock insists that "Gaia theory is testable", and lists some of the research spawned by the Gaia metaphor'. The investigations Lovelock cites, however, are generally not tests of the Gaia hypothesis, because "geophysiology" is unfalsifiably vague; negative results can be explained away simply by reinterpreting the theory.

For example, in 1987 Lovelock proposed that algae act as a global thermostat, producing dimethyl sulphide (DMS), a precursor of cloud condensation nuclei, to try to cool the Earth when it is warm ${ }^{3}$. Unfortunately, ice-core data published the next year suggested exactly the opposite. DMS levels are apparently highest during glacial periods; if the algae are important at all, they act to make the Earth even colder when it is cold ${ }^{+}$. Undeterred, Lovelock promptly inverted the theory to match the data. He now argues that Gaia actually prefers the glacial deep freeze, and that interglacial periods represent "a fevered state of the planet" 1.5 . How could anyone prove or disprove a "hypothesis" so ambiguous that it can predict one result, but also explain the exact opposite? And what could one do with it? Basing specific policy advice on such a fuzzy theory seems irresponsible.

It is ironic that Lovelock says Gaia "could be crucial to understanding the consequences of pollution and environmental disturbance". In the 1970 s, Lovelock himself used Gaia to argue against controlling chlorofluorocarbon pollution of the atmosphere, saying "We tend to forget that pollution is a way of life of many natural species . . . Our capacity to pollute on a planetary scale seems rather trivial by comparison, and the system does seem to be robust and capable of withstanding major perturbations" ${ }^{\text {. }}$. He now admits he may have been wrong, although he still sees fit to accuse his opponents from the 1970s of "global hypochondria"s.

Better understanding and preserving the global biogeochemical system will require a lot of difficult, important science, and we should get on with it. I hope that the Gaia metaphor will inspire interesting research into how that system works. We should be careful, however, not to pretend Gaia is a testable hypothesis, much less a basis for managing the biosphere. The risk is this: a metaphor like Gaia, flexible enough to be wrapped around almost any data set, is also versatile enough to be invoked, ad hoc, to lend a spurious air of scientific legitimacy to almost any reckless conjecture.

JAMES W. KIRCHNER

Division of Geological and Planetary

Sciences, $170-25$.

California Institute of Technology,

Pasadena,

California 91125, USA

1. Lovelock, J.E. Nature 344, 100-102 (1990)

2. Kirchner, JW Rev Geophysics 278, 223-235 (1989)

. Charlson, R. Lovelock, J.E., Andreae, M O. \& Warren S.G. Nature 326, 655-661 (1987).

4. Legrand, M.R., Delmas, R.J. \& Charlson, R.J. Nature 334, 418-420 (1988).

5. Lovelock, J.E. The Ages of Gaia (Norton, New York, 1988).

6. Schneider, S.H. in 1988 Yearbook of Science and the Future, 30-43 (Encyclopaedia Britannica, Chicago, 1987).

\section{Electronic journals}

SIR-John Maddox in his News and Views article "Towards the electronic journal" (Nature 344, 287; 1990) raised some interesting issues. In passing, a removable 45-megabyte hard-disk cartridge costs about $£ 100$, not $\$ 1,000$, and weighs as much as a copy or two of Nature. So one issue of Nature could comfortably sit within a megabyte, and the means to provide a year's issues on disk are already with us, magneto-optical disk technology notwithstanding.

Earlier this year, Sony announced two new products (neither of which will be commercially available for at least six months) both of which may cause a revolution in CD-ROM technology. The first is a rewritable $C D$ system, in itself not new, but this system should be only marginally more expensive than present $\mathrm{CD}$ players. It could easily be imagined that a six-pack CD peripheral could provide cheap, removable, on-line storage of 1.5-3 gigabytes at a fraction of the cost of present hard-disk systems, and without the usual fragility of floppy and hard disks. Transfer of the technology to video disks could allow storage of, say, 14 gigabytes.

The second product is an electronic book, based on a CD-ROM, with an LCD viewer. Each disk would offer 256 megabytes of storage, equivalent to about five years of Nature. As an alternative to LCD, Reflection Technology's Private Eye wearable viewing system offers a reasonable quality image (up to $1,024 \times 280$ pixels), and twin systems would allow three-dimensional imaging. Sony has not estimated a cost for the electronic book, but the alternative viewing system would start from only about $\$ 100$.

The $C D$ revolution offers many possibilities. A combination of ROM and RAM equivalents on $C D$ could provide an unerasable kernel of data with an appendix of either specialist terms or updates, for example, that could be rewritten by the user. Transmission of live video down an ordinary telephone line using compression techniques derived from fractal geometry offers the opportunity to transmit huge quantities of data in a very short space of time. Subscribers to Nature might be able to receive the week's issue, detailed photographs and all, by telephone.

What is more, CD-based literature can be immensely more informative than its paper-bound predecessor. Not only can typefaces be varied to suit the reader, but animated images can be readily provided. What remains to be seen is the power of the various forms of inertia likely to delay the implementation of these items. There are undoubtedly as many, if not more, interested parties keen to impede such changes as there are to produce them. It will be interesting to observe the outcome of the various skirmishes, and to see just how long it is before Nature is offered in $\mathrm{CD}$ form. If nothing else, CDs are considerably lighter and cheaper to post than paper counterparts.

96 Banbury Road, Oxford OX2 6JT, UK

\section{Two too many}

SIR-Some in Great Britain are apparently misinformed about developments in the former colonies.

John Maddox (Nature 8 March) ${ }^{1}$ identifies New Hampshire as "the state which is fiftieth (out of 52) in size," yet authoritative sources ${ }^{2}$ list only 50 states, of which New Hampshire currently ranks 44th in area and 39th in population. As Maddox implies, substantial growth beyond the original 13 colonies has indeed occurred, although the growth has been less than suggested.

Rand Corporation,

JAMES K. HAMMITT

1700 Main Street.

PO Box 2138,

Santa Monica.

California 90406-2138, USA

1. Maddox, J. Nature 344, 103 (1990)

2. Statistical Abstract of the United States, 109th edn. (US Department of Commerce, Bureau of the Census, 1989). 